3 Yiizeki, H., and Oono, K., Proc. Jap. Acad., 44, 554 (1968).

${ }^{1}$ Xitsch, J. P., and Nitsch, C., Science, 163, 85 (1969).

Kao, K. N., and Kasha, K. J., in Proc. Second Intern. Barley Genetics Symp., July 6-11, 1969 (edit. by R. A. Nilan) (Wash. State Cniv. Press, in the press).

"Gamborg, O. L., Miller, R. A., and Ojima, K., Exp. Cell Res., 50, 151 (1968).

"Lesins, K., Canad. J. Genet. Cytol., 3, 135 (1961).

'clement, W. M., Canad. J. Genet. Cytol., 5, 427 (1963).

"Hougas, R. S., Peloquin, S. J., and Ross, R. W., J. Hered., 49, 103 (1958).

"Wangenheim, K. H. V., Peloquin, S. J., and Hougas, R. S., Z. Verelung,, 91, $391(1960)$.

\section{Carbon Monoxide as a Basis for Primitive Life on Other Planets}

Is considering the possibility of life on other planets, we are naturally prejudiced towards some variant of the terrestrial photosynthotic mechanism for $\mathrm{CO}_{2}$ fixation. Such a prejudice is reasonable: photosynthesis is efficient and we know that it works. But there are reasons why such a cycle may not be likely on a planet such as Mars. The chemical machinery required for photosynthesis is exceedingly complex and is unlikely to be available to the most elementary organisms. Furthermore, on many planets, such as Mars, there is a considerable flux of high energy ultraviolet radiation which reaches the planetary surface ${ }^{1}$ and which will tend to rupture bonds in organic molecules. Because photosynthetic organisms must be exposed to light, it seems unlikely that they could survive for long in the face of this radiation. It is, of course, conceivablo that an organism could develop protective or self-repairing capabilities, but this would be particularly difficult for primitive life: in these conditions, life would bo casiest in the shade. This would disfavour, but not exclude, an energy cycle based on photosynthesis.

In looking for an alternative metabolic cycle and energy source, we should consider the fact that the atmosphere of primitive planets may well be predominantly $\mathrm{CO}_{2}$. This is the case for Mars and Vonus ${ }^{2}$. A small but significant fraction of the solar flux striking the atmosphere will be absorbed to dissociate $\mathrm{CO}_{2}$ to carbon monoxide ${ }^{\mathrm{I}, 3}$ :

$$
\mathrm{CO}_{2} \stackrel{h v}{\longrightarrow} \mathrm{CO}+\mathrm{O}
$$

Reoxidation of the $\mathrm{CO}$ (or a $\mathrm{CO}$ derivative) within an organism would provido a ready source of energy to drive metabolic reactions in which carbon is fixed and transformed into organic compounds. The complex chemical machinery required for transforming light energy into high energy chemical compounds is unnecessary, for this function is now carried on outside the organism. Furthermore, the living entity need not expose itself to any destructive ultraviolet flux.

A metabolic energy cycle based on oxidation of $\mathrm{CO}$ will certainly be far less efficient in terms of the utilization of the total solar energy striking the planctary surface. Only a fraction of a percentage $\left(2 \times 10^{-3}\right.$ per cent) of the total light energy flux is in the form of photons sufficiently energetic directly to dissociate $\mathrm{CO}_{2}$ (refs. 1 and 3 ), whereas of the order of 10 per cent may be useful for photosynthesis. ${ }^{4}$. Thus very primitive life forms subsisting on CO would eventually tend to be supplanted by more sophisticated photosynthetic organisms. Perhaps this has happened on Earth. On a planet like Mars, however, this subsequent phase might well not have occurred in view of the continuing prosence of the destructive ultraviolet flux, and because of the shortage of water.

There are two facts which further support this hypothesis of a metabolic energy cycle based on $\mathrm{CO}$. The first is that $\mathrm{CO}$ metabolizing organisms are known to exist on Earth. An example is Bacillus oligocarbophilus ${ }^{5}$, which seems to be widely distributed, and is particularly abundant in mines which contain appreciable amounts of CO.

The nature of the Martian atmosphere itself provides an interesting clue. If the $\mathrm{CO}_{2}$ is slowly photodissociated to $\mathrm{CO}$ and oxygen, why do we not see more of these latter species? Plausible mechanisms for efficient atmospheric recombination of $\mathrm{CO}$ and oxygen are hard to find, not only on Mars but on Earth ${ }^{3,6}$. It was on this basis that we suggested some years ago ${ }^{6}$ that terrestrial ${ }^{14} \mathrm{CO}$ produced by ${ }^{14} \mathrm{C}$ arising from cosmic radiation, as well as ${ }^{12} \mathrm{CO}$, was biologically oxidized by $B$. oligocarbophilus and similar organisms. Certainly, biological activity on Mars based on the oxidation of $\mathrm{CO}$ would provide a natural answer to the problem of why the Martian atmosphere is predominantly $\mathrm{CO}_{2}$ and contains so little of the expected $\mathrm{CO}$ and oxygen photodissociation products.

There are some obvious objections to this hypothesis. Perhaps the most serious is the inefficiency of the postulated process. But then, as has already been said, efficiency is not a requirement of the most primitive forms of life. It is only necessary that there is no more efficient process in direct competition. Another objection is the low concentration of $\mathrm{CO}$ and of oxygen, its probable oxidant. The molar fraction of $\mathrm{CO}$ in the Martian atmosphere is only 0.1 per cent ${ }^{2,7}$. Measurements of $\mathrm{O}_{2}$ have so far only given a rather high upper limit, $0 \cdot 3$ per cent (rof. 7 and personal communication from C. Barth). Because $\mathrm{O}_{2}$ is presumably produced by the same process which yields $\mathrm{CO}$, it is, however, plausible that these two species are present in similar concentrations. Obviously simultaneous collisions of $\mathrm{CO}$ and $\mathrm{O}_{2}$ molecules with an active site on an organism are unlikely. But relatively simple chemical forms are known to be capable of complexing and holding both $\mathrm{CO}$ and $\mathrm{O}_{2}$. It seerns plausible that an organism can thus accumulate both types of molecule and then cause the oxidation to proceed by an indirect route (Lederberg ${ }^{8}$ mentions the possibility of CO conversion on Mars, and suggests that the exergonic reaction $2 \mathrm{CO}+\mathrm{H}_{2} \mathrm{O} \rightarrow \mathrm{CH}_{2} \mathrm{O}+\mathrm{CO}_{2}$ might be involved). This mechanism provides a good example of the indirect path probably involved in such metabolism. Oxygen will be required for the eventual oxidation of organic material so produced, and this oxidation would then close the cycle. Finally, the fact that terrestrial organisms make do with a 0.03 per cent concentration of $\mathrm{CO}_{2}$ implies that low partial pressures are not necessarily a limitation.

This hypothesis seoms to be in accordance with known facts, but there may well be unknown factors which make it unlikely. It is not suggested that on a planet like Mars a life cycle based on $\mathrm{CO}$, or for that matter any life, is probable. But, if there is biological activity, it seems necessary to consider the hypothesis that it is based on the metabolism of CO.

It should be possible to search directly for $\mathrm{CO}$-fuelled life cycles by incubating planetary soil with ${ }^{14} \mathrm{CO}$ and looking for labelled metabolic products.

These views have been stimulated by laboratory experiments supported by the US National Aeronautics and Space Administration and the US Atomic Energy Com. mission and discussions with W. F. Libby and others.

Departmont of Chemistry,

Richard WoLfGaNG*

University of Colorado,

Bouldor.

Received January 16, 1970.

* Present address: Department of Chemistry, Yale University, New IIaven, Connecticut.

${ }^{1}$ Johnson, F. S., Satellite Environment Handbook, 98 (Stanford Univ. Press, 1965).

${ }^{2}$ Goody, R. M., Atmosphere of Venus and Mars (edit. by Brandt, J. C., and McElroy, M. B.) (fiordon and Breach, 1968).

3 Bates, D. R., The Earth as a Planet (edit. by Kuyper, G. P.) (Chicago, 1964).

4 NAS-NRC, Biology and the Exploration of Lars, 230 (Publication 1296, 1966).

${ }^{5}$ Stephenson, M., Bacterial Metabclism, third ed. (Tongmans, Green, Iondon, 1949).

'Pandow, M., MacKay, C., and Wolrgang, R., J. Tnorg. Nucl. Chem., 14, 153 $(1960)$.

7 Belton, M. J. S., and Hunten, D. M., Astrophys. J., 153, 963 (1968).

${ }^{8}$ Lederberg, J., Applied Optics, 8, 1269 (1969). 